\title{
Estrategias sindicales \\ e iniciativas estatales en el sector del servicio doméstico en la ciudad de Buenos Aires: el impulso y sus límites
}

Ania Tizziani

Doctora en sociología (Universidad París 1 - Panthéon Sorbonne) Investigadora Conicet con sede en el Instituto de Ciencias, Universidad Nacional de General Sarmiento, Provincia de Buenos Aires, Argentina. atizzian@ungs.edu.ar

\begin{abstract}
Resumen
El empleo doméstico constituye una de las principales fuentes de empleo femenino urbano en Argentina. Como en otros países de la región, ésta ocupación se ha caracterizado, históricamente, por el peso elevado de la informalidad y por el retraso de la legislación específica que la regula con respecto al marco general de las leyes del trabajo. Sin embargo, desde hace una década, el sector registra profundas transformaciones que conciernen particularmente la regulación estatal. Dichos cambios implicaron en la extensión de las posibilidades de acceso al empleo registrado y a las protecciones sociales para un gran número de empleadas domésticas. Estas iniciativas se acompañaron de la puesta en práctica de programas de formación y capacitación específicamente dirigidos a las empleadas domésticas que, en la ciudad de Buenos Aires, han sido desarrollados con la participación activa de una de las organizaciones sindicales del sector. Sobre la base de un estudio cualitativo, el objetivo de este artículo es analizar los efectos de estas transformaciones en el funcionamiento de las organizaciones sindicales del sector y la relación que éstas establecen con las trabajadoras.
\end{abstract}

Palabras clave: trabajo domestico; sindicatos; capacitacion; Argentina.

$\mathrm{E}$ L SERVicio doméstico COnStituye, en Argentina como en la mayoría de los países latinoamericanos, una de las principales fuentes de empleo femenino urbano. A fines de 2009, casi un millón de trabajadoras se inserta en este sector de actividad, representando cerca de un 14\% de las asalariadas (Contartese, 2010). Históricamente, como en otros países de la región, esta categoría de trabajadoras se caracterizó por ser una de las más relegadas. El sector presenta condiciones salariales y de trabajo que se encuentran entre las más desfavorables del mercado de trabajo argentino. Asimismo, uno de los rasgos de esta ocupación ha sido el hecho de desarrollarse, mayoritariamente, por fuera de todo marco legal. Aún cuando la legislación que regula el sector es respetada, esta actividad se caracteriza por el bajo nivel de las protecciones sociales y los derechos restringidos a los que tiene acceso esta categoría de trabajadoras respecto del resto de las asalariadas.

Ahora bien, en las últimas décadas, el sector registra profundas transformaciones que conciernen particularmente la legislación laboral y diversas iniciativas estatales. En el año de 2000, se dicta el Régimen Especial de Seguridad Social para Empleados del Servicio Doméstico, que amplía las posibilidades de acceso a prestaciones de salud y jubilatorias para las trabajadoras del sector. Cinco años más tarde la Administración Federal 
de Ingresos Públicos (AFIP) y el Ministerio de Trabajo, Empleo y Seguridad Social (MTEySS), implementan un programa de regularización de las trabajadoras domésticas que desemboca, según esos organismos, en un crecimiento acelerado del empleo registrado. Estas iniciativas se acompañaron de una amplia campaña de difusión y comunicación y de programas de formación profesional específicamente dirigidos a esta categoría de trabajadoras. En la ciudad de Buenos Aires, estos programas fueron desarrollados con la participación activa de uno de los sindicatos de empleadas domésticas, la Unión del Personal Auxiliar de Casas Particulares (UPACP), que jugó un rol importante en la puesta en práctica y en el diseño de los cursos de capacitación

El objetivo de este artículo es analizar los efectos de estas múltiples iniciativas estatales sobre la organización sindical de las trabajadoras domésticas. El contexto de crecimiento del empleo registrado, de aumento de la visibilidad pública de las problemáticas vinculadas al trabajo doméstico remunerado y la participación de una de las agrupaciones sindicales en esas iniciativas, contribuye a crear condiciones favorables al desarrollo de la organización de estas trabajadoras. En particular, este contexto facilitó el contacto entre los sindicatos y sus potenciales afiliadas, pese a las dificultades que caracterizan la agremiación en este sector de actividad. A través de un estudio cualitativo localizado en el sindicato que participó de esas iniciativas estatales, nos interesa analizar las transformaciones que este contexto favorable ha introducido en el funcionamiento de la entidad y en la manera en que ésta se relaciona con las trabajadoras.

\section{Perfil socio-económico y marco legal}

El servicio doméstico constituye en Argentina un sector altamente feminizado, dado que las mujeres representan el 98,5\% de la población ocupada en estas actividades. Esta población cuenta con un nivel educativo menor del que se constata en el resto de las asalariadas.
En efecto, el 75\% de las asalariadas del sector alcanzó como máximo el nivel de educación "secundario incompleto", mientras que para el resto de las asalariadas ese porcentaje se reduce al $22 \%{ }^{1}$. La mayoría de las mujeres que se ganan la vida a través del trabajo doméstico remunerado proviene de sectores categorizados como pobres o indigente y más de un $43 \%$ son migrantes ${ }^{2}$. Las empleadas domésticas se sitúan entre los grupos con más bajos niveles de ingresos individuales ${ }^{3}$ : el $74 \%$ de las trabajadoras del sector se encuentran en el primer quintil de ingresos. En lo que se refiere a la situación laboral, según los datos oficiales, cerca del $72 \%$ de las ocupadas del servicio doméstico en 2009 trabaja para apenas un empleador y la mayoría lo hace dentro de la modalidad "con retiro". En efecto, la proporción de empleadas que residen en el domicilio del empleador se habría reducido fuertemente durante las últimas décadas, representando, ese mismo año, sólo 3\% de las ocupadas en el servicio doméstico.

Las empleadas domésticas constituyen una de las categorías de trabajadores que se encuentran expresamente excluidas del marco general de la Ley de Contrato de Trabajo y regidas por un estatuto específico ${ }^{5}$. Los llamados estatutos profesionales tienen por objetivo establecer un régimen particular para aquellas actividades que, por sus características, no pueden ser reguladas en su totalidad por la ley laboral común. En el año 1956 se dictó el primer marco legal para las actividades del sector a través del Estatuto del Servicio Doméstico (Decreto-Ley 326/1956), que es el que aún está en vigencia. Los estudios disponibles sobre esta forma de empleo en la Argentina coinciden en señalar el retraso de esta legislación específica referente al marco general de las leyes laborales en términos del nivel de protección de los trabajadoresa (Gogna, 1993, Machado, 2003).

El estatuto considera como asalariados en el servicio doméstico aquellos empleados que residan en el domicilio del empleador o quienes trabajen como mínimo cuatro horas por día, cuatro días a la semana para el mismo empleador. Regula los niveles mínimos de salarios para las diferentes categorías de empleadas domésticas ${ }^{6}$, los aportes patronales a la seguridad social y establece el derecho a vacaciones anuales y

1 Todos los datos estadísticos que presentamos en este párrafo provienen del informe Caracterización del Servicio Doméstico en la Argentina, elaborado por la Subsecretaría de Programación Técnica y Estudios Laborales del MTEySS.

2 De las cuales el $32,6 \%$ proviene de otra provincia y el $11 \%$ de otro país. Se trata sin embargo, en su gran mayoría, de migraciones no recientes dado que un $96,2 \%$ de las empleadas domésticas cuenta con 5 años o más de residencia en la localidad en la que se encontraba al momento de la encuesta.

3 Los datos aquí presentados están basados en la Encuesta Permanente de Hogares (EPH), que computa tanto los ingresos individuales (percibidos por una persona) como los ingresos de los hogares (percibidos por el conjunto de los miembros de una unidad doméstica).

4 Es decir, residiendo en su propio domicilio.

$\mathbf{5}$ La Ley de Contrato de Trabajo (Ley 20.744) constituye la columna vertebral del derecho laboral argentino. En su artículo 2 estipula que sus disposiciones no son aplicables a los empleados públicos (nacionales o municipales), a los trabajadores agrarios y del servicio doméstico.

6 Esta legislación diferencia cinco categorías de trabajadores domésticos según el nivel de especialización y la modalidad de trabajo, residencial o externa. 
aguinaldo. También contempla el derecho a licencias por enfermedad, indemnización y preaviso en caso de despidos, que son sin embargo menores en comparación con el régimen general. Las empleadas domésticas están excluidas de la ley de asignaciones familiares y de riesgos de trabajo. No perciben remuneración por horas extras, no pueden acceder a un seguro de desempleo, ni cuentan con licencias por maternidad. De igual forma, la legislación fija una duración de la jornada de trabajo para las empleadas que residen en el domicilio del empleador que puede ser de 12 horas, con un descanso semanal de 24 horas. La semana laboral de las empleadas domésticas "sin retiro" puede alcanzar, por ley, 72 horas, 24 horas más de lo que estipula el régimen general. Los salarios mínimos son fijados a través de reglamentaciones del MTEySS, y se sitúan generalmente por debajo del salario mínimo general ${ }^{7}$.

El alcance del marco regulatorio que establece el Estatuto del Servicio Doméstico es sin embargo limitado. En efecto, en función de las situaciones de trabajo imperantes en el sector, el 60\% de las empleadas domésticas podía acceder a la condición de asalariadas y ser comprendidas dentro de esta legislación ${ }^{8}$. El $40 \%$ restante es incorporado dentro de la categoría de trabajador independiente, que debe realizar sus propias contribuciones a las instituciones de la seguridad social. Esta situación fue modificada por el Régimen Especial de Seguridad Social para Empleados del Servicio Doméstico9. Esta norma implica la ampliación de las posibilidades de acceso a prestaciones de salud y jubilatorias para las trabajadoras del sector ya que establece la obligatoriedad de las contribuciones patronales para las empleadas independientes que trabajan por lo menos 6 horas semanales para un mismo empleador. Según los datos del MTEySS, esta norma extiende las posibilidades de acceso a las prestaciones de la seguridad social a más de un $90 \%$ de las empleadas domésticas. Cabe destacar que el acceso a estas prestaciones queda supeditado a un aporte adicional que deben realizar las trabajadoras.

La situación de las empleadas domésticas independientes es profundamente ambigua en lo que se refiere al marco protectorio al que tienen acceso. Por un lado, éste estipula la obligatoriedad, para el empleador, de realizar parte de sus aportes a la seguridad social. Por el otro, no tienen acceso a las protecciones del derecho laboral asociadas a la relación de dependencia: el nivel mínimo de remuneraciones no está regulado, no tienen acceso a licencias y vacaciones pagas, preaviso en caso de despidos, aguinaldo anual u otros beneficios sociales, ni cuentan con un marco que brinde las pautas para la gestión de la relación de trabajo. Si bien esta nueva legislación implica la ampliación de las posibilidades de acceso a las protecciones sociales para un mayor número de empleadas domésticas, al reforzar el estatuto de trabajador "autónomo" no hace más que acentuar la tendencia a la individualización de la gestión de esta relación laboral. De esta manera, una de las categorías de trabajadoras más desfavorecidas en términos del nivel de ingreso, debe gestionar, por sí misma, tanto los riesgos asociados a la inestabilidad en el empleo, como la negociación de sus condiciones salariales y de trabajo en una relación personalizada con los empleadores. Estas características específicas del marco regulatorio dificultan la conformación de una categoría homogénea de trabajadoras en este sector de actividad y tiene efectos importantes sobre el funcionamiento de sus organizaciones sindicales.

\section{Formalizar y profesionalizar}

Históricamente, el cumplimiento efectivo de este marco regulatorio ha sido extremadamente reducido. En 2005, sólo el 5\% de las empleadas domésticas estaban registradas en las instituciones de la seguridad social y un porcentaje muy reducido tenía acceso a otros beneficios laborales. Frente a esa situación, a fines de ese mismo año, el MTEySS y la AFIP implantaron conjuntamente un programa de regularización del empleo doméstico basado en dos estrategias principales: la simplificación de la inscripción de los trabajadores y la aplicación de incentivos económicos ${ }^{10}$. Estos incentivos conllevan, concretamente, la posibilidad, para el empleador, de deducir en el impuesto a las ganancias los aportes a la seguridad social y la totalidad del sueldo de la empleada doméstica, con un tope de $\$ 9000$ a partir del año de 2008. Según las cifras oficiales, este programa desembocó en un crecimiento significativo del empleo registrado en el sector, que alcanzó casi un 15\% a fines de 2009 (Contartese, 2010)

Este programa de formalización se acompañó de una amplia campaña de difusión y comunica-

7 El último aumento del salario mínimo de las empleadas domésticas, que tuvo lugar en enero de 2011 , lo fijó en \$1.657 para las trabajadoras no especializadas, a tiempo completo, en las modalidades "con retiro" (que son las más numerosas) y equiparó el salario de aquellas que trabajan "sin retiro" con el salario mínimo general, que fue fijado, ese mismo mes, en $\$ 1.840$.

8 Según datos del MTEySS, ese porcentaje corresponde a las empleadas domésticas que residen en el domicilio del empleador o que trabajan por lo menos cuatro horas, cuatro días a la semana para el mismo empleador (Contartese, 2009).

9 Ley 25.239, diciembre de 1999.

10 Para la caracterización de este programa de blanqueo del empleo doméstico ver los estudios elaborados por la AFIP Estimación de la Informalidad Laboral (2003-2006) y Administración Tributaria y Cohesión Social, 2009. 
ción y de la implementación de programas de capacitación específicamente dirigidos a las trabajadoras del sector. Con el objetivo de "jerarquizar" y profesionalizar" el trabajo doméstico remunerado, estos programas consisten en una variada oferta de cursos gratuitos de formación profesional, así como la asistencia técnica y financiera a las instituciones que los organizan y dictan, asociativas o sindicales. Además de aquellos participantes que se acercan espontáneamente a los cursos a través del sindicato o de la obra social del sector, el público está compuesto por los beneficiarios de los Planes de Capacitación y Empleo, otorgados por el gobierno nacional a trabajadores desempleados, que deben cumplir actividades de capacitación como contrapartida. Este programa específico dirigido a los trabajadores del servicio doméstico busca, por una parte, contribuir al mejoramiento de las condiciones salariales y de trabajo dentro esta actividad, a través de la adquisición de competencias acreditadas, que vayan en el sentido de la especialización del empleo. Por otra parte, al mejorar la "empleabilidad" de las personas, el programa busca promover la movilidad hacia otro tipo de empleos, en sectores cercanos o afines.

Es por esta razón que la oferta de cursos es particularmente amplia. Algunos de ellos están específicamente vinculados al trabajo en el servicio doméstico, como los cursos de "Servicios a casas particulares", "Servicios en espacios verdes" y "Atención y cuidado de personas", cuyo dictado está a cargo, en la ciudad de Buenos Aires, de la UPACP y la obra social vinculada a esa entidad. Otros cursos, en cambio, tienden a favorecer la movilidad hacia otras actividades como los de "Servicios de limpieza institucional", "Servicios turísticos, gastronómicos y de salón" y "Servicios varios (textiles, estéticos y otros") etc. Este programa tenía, en 2010, la meta de formar cerca de 3.000 hombres y mujeres en 16 provincias del país ${ }^{12}$.

Las transformaciones en la regulación estatal y estas diversas iniciativas públicas contribuyeron a conformar un contexto favorable a la sindicali- zación de las trabajadoras del sector. El aumento del empleo registrado y la extensión de las posibilidades de acceso a una cobertura de salud para un mayor número de empleadas domésticas han reforzado el rol de las organizaciones sindicales y de la obra social del sector. Nos interesa, en el siguiente apartado, analizar las transformaciones que este contexto ha introducido en su funcionamiento y en el modo en que se relaciona con las trabajadoras ${ }^{13}$.

\section{La organización sindical de las empleadas domésticas: un estudio de caso en la ciudad de Buenos}

\section{Aires}

Diferentes estudios destacan la importancia de la relación entre las iniciativas públicas-estatales y la organización sindical de los trabajadores; una relación que se verifica en un doble sentido. Por una parte, las iniciativas público-estatales en materia de regulación de las condiciones de trabajo y salariales de un sector de actividad no son ajenas al grado de organización colectiva de los trabajadores y su capacidad de negociación frente a otros sectores y el Estado. En el contexto latinoamericano, la capacidad de una categoría de trabajadores para constituirse en tanto actor organizado en la escena pública, juega un rol particularmente importante en el acceso y las características de las políticas de protección social del sector. Como señalan Barbeito y Lo Vuolo "Los estudios acerca del origen y expansión de los sistemas de protección social latinoamericanos contrastan dos dinámicas políticas. Por un lado, se enfatiza el papel de los grupos de presión política identificados generalmente con sectores laborales, que fueron obteniendo beneficios diferenciados al Estado; por otro lado, se señala a las élites gubernamentales otorgando beneficios segmentados con el objetivo de cooptar a ciertos grupos. El resultado de estas dinámicas, es una organización política de los sistemas de protección social,

11 Veremos que este objetivo de "jerarquización" es también reivindicado por los actores sindicales. Se trata de revalorizar el trabajo doméstico remunerado a través de la adquisición de competencias específicas, acreditadas por organismos oficiales, por parte de los trabajadores que se insertan en el sector.

12 La descripción detallada de estos programas de capacitación está disponible en el sitio web del MTEySS: <http://www.trabajo.gob.ar/capacitacion/domestico/?seccion=domesticos

13 Las reflexiones que siguen están basadas en un trabajo de campo cualitativo realizado entre agosto de 2008 y octubre de 2009 en la ciudad de Buenos Aires, que estuvo en parte localizado en uno de los sindicatos de empleadas domésticas más importantes de la ciudad, UPACP (Unión de Personal Auxiliar de Casas Particulares). Se realizaron un total de 10 entrevistas en profundidad entre las autoridades del sindicato, las encargadas de la atención al público, las responsables de la Escuela de capacitación y las profesoras. Se realizaron además cerca de 15 entrevistas entre las participantes de los cursos y las afiliadas, así como observaciones repetidas (que fueron registradas en un diario de campo) de las actividades, los cursos de capacitación y de las salas de espera de los diferentes locales del sindicato. 
donde una suerte de "inclusión" selectiva en los diseños institucionales convive en permanente tensión con un discurso universalista de reconocimiento de derechos igualitarios para toda la ciudadanía" (Lo Vuol y Barbeito, 1998, p. 45). En el caso argentino, las políticas de protección social del empleo doméstico respondieron principalmente a estrategias gubernamentales, con escasa participación de las trabajadoras en tanto actor organizado en la escena pública, en lo que se podría llamar una inclusión diferenciada a algunos beneficios y protecciones sociales.

Por otra parte, como muestran los análisis de Marshall y Perelman, la normativa legal constituye uno de los factores que intervienen en el desarrollo de las organizaciones sindicales, incidiendo en la afiliación individual a los sindicatos. En efecto, las regulaciones referidas a las organizaciones gremiales, a las convenciones colectivas de trabajo y a la seguridad social, entre otras, pueden propiciar o desalentar directa o indirectamente la afiliación y afectar las estrategias sindicales de reclutamiento de miembros (Marshall; Perelman, 2004). Esta influencia es aún más relevante en el caso de las empleadas domésticas, donde su exclusión del marco general del derecho laboral, en la mayoría de los países de la región, ha operado como un obstáculo a la organización colectiva (Chaney, 1993, p. 14). De hecho, algunos países cuentan incluso con normas que explícita o implícitamente impiden la organización de las trabajadoras domésticas (OIT, 2009).

Estos obstáculos se suman a las dificultades que plantean las especificidades del trabajo en el servicio doméstico a la organización de las trabajadoras. En efecto, la fragilidad de las entidades gremiales de aquellas que se desempeñan en esta actividad es destacada por la mayoría de los estudios que abordan esta forma de empleo para los diferentes casos latinoamericanos. La dispersión de los lugares de trabajo y el aislamiento dentro del domicilio privado del empleador, es uno de los factores más destacados por los diferentes estudios. El peso de la informalidad, que ha sido históricamente muy elevado en esta forma de empleo, no ha favorecido la agremiación de las trabajadoras (Lautier, 2003). La gran heterogeneidad de las situaciones de trabajo y de las características de las ocupadas (en particular en relación con la condición migratoria), ha dificultado la articulación de las demandas en torno de objetivos comunes (Golsdmith, 2007). La débil identificación con una actividad fuertemente desvalorizada, que es con frecuencia concebida como un empleo transitorio, tampoco ha propiciado la afiliación (Schelleken; van der Schoot, 1993, p. 263).

Pese a esas dificultades, las organizaciones de trabajadoras domésticas existen en la mayoría de los países latinoamericanos. En algunos casos, como en el brasilero, éstas cuentan con trayectorias de varias décadas en las ciudades más importantes y han contribuido fuertemente al mejoramiento de las condiciones salariales y laborales en el sector (Vidal, 2007). Sin embargo, su mayor debilidad se sitúa en el escaso y muchas veces inestable nivel de participación de las trabajadoras que representan. Veremos que ésta es una de las características que definen también las experiencias de sindicalización en el caso argentino. Según los registros del MTEySS, hay actualmente 20 agrupaciones sindicales de empleadas domésticas a nivel nacional. Las dos organizaciones localizadas en la ciudad de Buenos Aires cuentan con una trayectoria de más de medio siglo, pero su peso ha sido históricamente reducido. Resulta difícil sin embargo, contar con un panorama general de la organización colectiva de las empleadas domésticas en el país, por un lado debido a la falta de información oficial actualizada, por el otro, por la renuencia que muestran los representantes sindicales para brindar datos precisos de afiliación.

La Unión del Personal Auxiliar de Casas Particulares (UPACP) es el sindicato más importante en términos del número de afiliadas en la ciudad de Buenos Aires. Según sus autoridades - y como puede leerse en los folletos de presentación del sindicato - éste fue fundado en 1901, pero la personería gremial fue otorgada por el MTEySS en $1947^{14}$. Según su secretaria general, cuenta con un padrón de unos 23.000 miembros - en su gran mayoría mujeres - que en sus propias palabras, "no está depurado" de aquellas que han sido afiliadas pero que ya no participan del sindicato. Al ser el sindicato con mayor número de afiliadas en la ciudad, éste detenta el monopolio de la representación del conjunto de las trabajadoras del sector.

En efecto, uno de los rasgos que caracterizan la estructura sindical argentina, es el monopolio de la representación por parte del sindicato más importante en un determinado sector de actividad. Desde la expansión de la sindicalización en los años 1945-55, ésta se basa en el sector de la actividad económica, antes que en el oficio o la empresa particular. En cada sector de actividad, sólo se otorga al sindicato que reúne la mayor cantidad de afiliados, la capacidad para negociar con los empleadores u organismos estatales. Los salarios y las condiciones establecidas en esas negociaciones se extienden a todos los trabajadores de la actividad y no sólo a los agremiados. La estructura sindical está, a su vez, fuertemente centralizada, ya que las ramas locales ascienden, por intermedio de federaciones nacionales, hasta una única central, la Confederación General del Trabajo (CGT) (James, 1990, p. 23).

14 El 12 de mayo de 1901 se fundó el Sindicato del Personal Doméstico en Argentina, que se transformó en la Unión del Personal Auxiliar de Casas Particulares en 1946 
Dentro de esta estructura sindical, desde los años 60, los servicios sociales (médico asistenciales primero y, progresivamente, turísticos, recreativos, de capacitación, etc.) brindados por los gremios comienzan a adquirir una importancia creciente. A partir de los años 1970, los sindicatos que detentan el monopolio de la representación van a ser los encargados de gestionar la provisión de los servicios médico asistenciales al conjunto de los trabajadores de la actividad y recibir los aportes obligatorios que la ley establece para trabajadores y empleadores. Esta legislación obliga a dichas entidades gremiales a fundar una obra social, desvinculándose la afiliación al sindicato del acceso a los servicios médico asistenciales que ésta brinda. Más allá de las variaciones de la normativa, sindicatos y obras sociales constituyen entidades formalmente diferenciadas, pese a que las organizaciones gremiales conservan un margen de injerencia en el funcionamiento y el uso de recursos de las obras sociales ${ }^{15}$. Sin embargo, en la práctica, la frontera entre ambas entidades se vuelve borrosa y el sistema de obras sociales constituye un soporte importante para el reclutamiento de miembros, en particular en aquellas actividades con escasas posibilidades de desarrollo de la representación de base (Marshall; Perelman, 2004).

En el caso del sector del servicio doméstico, la obra social vinculada a la UPACP, OSPACP (Obra Social del Personal Auxiliar de Casas Particulares), fue fundada en 1975. Los cambios recientes en el marco legal del servicio doméstico, al impulsar el empleo registrado y ampliar las posibilidades de acceso a las prestaciones de salud para un mayor número de empleadas domésticas, han dado un impulso importante al desarrollo de la obra social. En efecto, según las declaraciones de sus responsables, ésta ha tenido un crecimiento particularmente acelerado en la última década, pasando de 15.000 afiliadas a mediados de la década del '90 a 200.000 en el año de 2010. Esto ha implicado también un aumento importante en los recursos de la obra social, que se ha traducido en la apertura de nuevas sedes en diferentes provincias y la ampliación de su oferta de servicios.

El crecimiento de la obra social trajo aparejado un impulso significativo en la afiliación al sindicato. Como destaca en una de nuestras entrevistas la secretaria general de UPAPC: "Todo esto fue creciendo. Al principio, obviamente, había donaciones. Nos juntábamos y veíamos qué podíamos hacer. Ahora, gracias a Dios, va creciendo el gremio con sus afiliadas. Nuestro sindicato, nuestra obra social están en crecimiento. No es una obra social grandísima, pero dentro de todo lo que nosotros podemos hacer le brindamos todo lo que podemos a la afiliada". Si bien el sindicato y la obra social cuentan con sedes y autoridades diferentes, en los discursos de sus responsables, existe una fuerte imbricación entre ambas entidades. De hecho, algunas actividades que juegan un rol central en los discursos de ambas organizaciones, como es el caso de las que desarrolla la escuela de capacitación, son llevadas a cabo de manera conjunta por el sindicato y la obra social.

La UPACP cuenta con dos líneas de acción principales. La primera está vinculada al desarrollo de sus redes institucionales. La segunda a la provisión de una serie de servicios específicamente dirigidos a las empleadas domésticas. En cuanto a la primera línea de trabajo, se organiza en torno del establecimiento de vínculos con otras organizaciones sindicales, asociaciones y sobre todo representantes estatales. Por una parte, la UPACP está afiliada a la CGT, lo que extiende sus redes institucionales a otras entidades sindicales. Cuenta por otra parte, con acciones regulares frente al MTEySS para negociar mejoras salariales u otros aspectos de la normativa, además de convenios con diferentes organismos públicos para desarrollar iniciativas en forma conjunta.

La importancia de la consolidación de esa relación con organismos estatales en el contexto actual de crecimiento del sindicato se manifiesta claramente en el discurso de sus responsables. Como señalaba su secretaria general en una de nuestras entrevistas: "Ahora nos abrieron las puertas. Antes no podíamos hacer nada. Por ahí había un apoyo, pero no lo suficiente. Ahora, entre la AFIP, el Estado, el gobierno, seguridad social... la obra social y el sindicato se hizo un conjunto y podemos ir todos para el mismo lado". Esta consolidación de la relación con organismos estatales y el fortalecimiento del rol del sindicato no pueden ser desvinculados de un contexto de resurgimiento de las entidades gremiales en la escena política argentina. En efecto, desde el año 2003, el país registra una importante reactivación económica y una recuperación de los niveles de empleo ${ }^{16}$. Este proceso se acompaña, a su vez, de una recuperación progresiva de las instituciones laborales, de la mano del fortalecimiento

15 La legislación estipula la separación administrativa financiera y patrimonial, aunque no hay incompatibilidad de cargos entre ambas instituciones y un $8 \%$ de los recursos de las obras sociales pueden ser destinados, según el criterio de cada sindicato, al desarrollo de otras prestaciones sociales que no sean servicios de salud (Marshall; Perelman, 2004, p. 12).

16 La tasa de desocupación abierta se reduce al 20\% en el primer trimestre de 2003 y al $8 \%$ a fines de 2009 . Sin embargo, pese a esta recuperación del empleo, la proporción de trabajo no registrado se mantiene en niveles particularmente elevados (cerca del $40 \%$ de la población ocupada). 
de la intervención de MTEySS y de la legislación laboral que da marcha atrás sobre algunas de las disposiciones flexibilizadoras de la década de 1990. En ese contexto, se produce un renovado protagonismo de las organizaciones sindicales que es visible en el aumento del conflicto laboral, en una recuperación de la tasa de afiliación y en el crecimiento de las negociaciones colectivas (Senén González; Haidar, 2009, p. 10).

Sin embargo, pese a ese contexto favorable, los responsables de la UPACP destacan la posición de fragilidad del sindicato frente a sus interlocutores institucionales, ya sean las otras organizaciones gremiales agrupadas en la CGT o los representantes gubernamentales. La UPACP es una entidad que nuclea casi exclusivamente mujeres, en un contexto sindical ampliamente dominado por representantes masculinos. Como no dejaron de señalar las representantes del sindicato de empleadas domésticas, esta situación pesa sobre los vínculos que éste establece con otras organizaciones gremiales: "Es una lucha...somos pocas mujeres las que estamos dentro de los gremios, somos sólo dos secretarias generales mujeres. O sea, imagínate... entre tantos hombres, ¡hay que imponerse!”. Por otra parte, las mujeres representadas por UPACP se desempeñan en una actividad fuertemente desvalorizada, como se desprende de la siguiente cita, donde un asesor del sindicato describe una reunión con representantes de otros gremios para presentar el proyecto de crear la escuela de capacitación: "qué les voy a hablar de capacitación para el servicio doméstico, si te dicen '¡andá a lavar los platos!'...”. Pese al afianzamiento de los vínculos con los representantes gubernamentales, también allí se manifiesta la desvalorización que pesa sobre esta forma de empleo: "No se tiene en cuenta el servicio doméstico. Lo tienen por el piso. Nunca podemos lograr lo que nosotros queremos, porque si pedimos una audiencia con fulano, justo ese día tiene que ir a otro lado o tienen otro problema. ¡Hay que pelearlo dos, tres, cuatro, cinco veces!".

Frente a esa fragilidad de la posición institucional del sindicato, no es de extrañar que opte por privilegiar la segunda línea de trabajo, centrada en el desarrollo de una oferta de servicios específicamente dirigidos a las empleadas domésticas. El sindicato cuenta con un servicio de atención al público en horario extendido, cuya función es brindar, tanto a empleadas como a empleadores, información sobre los salarios, los derechos y las condiciones de trabajo que estipula la legislación vigente, así como asesorar sobre los trámites a realizar para el pago de los aportes jubilatorios y la obra social.
Cuenta además con consultorías legales, cuyos abogados atienden generalmente dos o tres días a la semana, en horas de la tarde, para casos de conflicto entre empleadas y empleadores. Los abogados del sindicato pueden eventualmente representar a las afiliadas en los juicios presentados ante el Tribunal del Servicio Doméstico ${ }^{17}$. La UPACP cuenta además con una bolsa de trabajo particularmente activa.

En el año 2006, junto con la obra social y con apoyo del MTEySS, funda la Escuela de Capacitación para Empleados del Servicio Doméstico. Con el objetivo de "jerarquizar y profesionalizar" el trabajo doméstico remunerado, ofrece cursos de capacitación específicamente vinculados a esta ocupación: servicios generales de limpieza, organización del hogar, cocina, lavado y planchado de ropa, atención a terceros, jardinería. Todos esos cursos contienen un módulo que aborda los "derechos y obligaciones de empleados y empleadores del servicio doméstico", centrado en la legislación laboral. También ofrece cursos de escolarización primaria, secundaria y de inglés. Organiza además, encuentros, viajes y otras actividades recreativas. Según sus organizadoras, la recepción de los cursos ha sido muy positiva: cerca de 200 alumnas en 2008 y 300 en 2009 han pasado por sus aulas ${ }^{18}$. La mayoría de ellas llega a través de los planes de empleo del gobierno y de la obra social.

La escuela de capacitación constituye una iniciativa central en los discursos de los representantes sindicales. Por un lado, le ha dado mayor visibilidad a la entidad gremial y ha facilitado el contacto con sus potenciales afiliadas. Como señalaba, en uno de nuestros encuentros, una de las organizadoras de los cursos: "Los cursos son sólo para afiliadas, en general llegan por la obra social y de paso, vienen y se afilian al sindicato". Por otro lado, esa iniciativa cumple un rol central en el objetivo del sindicato de "jerarquizar y profesionalizar" el trabajo en el servicio doméstico. Ante la fragilidad de su posición frente a sus interlocutores institucionales, la entidad gremial busca consolidarse a través de la construcción y la revalorización de una identidad profesional de pertenencia para sus representadas. Para ello, resulta fundamental homogeneizar una categoría de trabajadoras, con calificaciones y competencias específicas, que no son ya asimiladas a una suerte "condición natural" femenina. Esa estrategia de la entidad gremial pasa entonces por la "estandarización" de los saberes técnicos implicados en las prácticas de trabajo, de las competencias y sus certificaciones. Veremos que las características específicas de este sector de actividad plantean obstáculos importantes en el avance hacia esos objetivos.

17 Este tribunal, que depende del MTEySS, fue creado por el Estatuto del Servicio Doméstico y constituye el organismo competente para atender los conflictos individuales que deriven de las relaciones de trabajo que se inscriban en este sector de actividad.

18 Los cursos que cuentan con un público más numeroso son aquellos vinculados a las tareas del servicio doméstico. En 2008, había 150 alumnas inscriptas en el ciclo de "profesionalización del servicio doméstico" y 50 en escolarización primaria y secundaria. 


\section{Desde la perspectiva de las trabajadoras: experiencia individual y sociabilidad}

"Es golondrina. Nosotros decimos que es un gremio golondrina". La expresión de la secretaria general del sindicato resume bien la problemática principal del gremio en la relación con sus afiliadas: "Se vienen a afiliar y después de un tiempo no vienen y después vuelven otra vez...". Como destacan casi todos los estudios sobre esta forma de empleo en diferentes países latinoamericanos, una de las principales problemáticas de sus organizaciones sindicales se vincula con las dificultades para generar la participación sostenida de las mujeres que la ejercen.

Una visita a la sede central de la UPACP, en horas de la tarde, durante los días en los que atienden los abogados, parece, a primera vista, desmentir esa regla general. Las recepcionistas atienden al público, instaladas en dos escritorios de cara a una pequeña sala de espera, donde unas diez mujeres conversan mientras esperan la llegada de los abogados. Esas mujeres que esperan forman parte, sin embargo, de una porción reducida del universo de las empleadas domésticas. Como señalaba en una entrevista una de las recepcionistas, se trata de las "privilegiadas", de aquellas que "trabajan en la Capital Federal, están en blanco, estables, tienen obra social y están sindicalizadas". En todo caso, una serie de requisitos delimitan claramente el universo de empleadas que puede acceder a la afiliación. Para ello, es necesario contar con un documento de identidad argentino, un certificado de antecedentes penales y de domicilio, además del pago de una reducida cuota mensual ${ }^{19}$. Si bien la atención al público es accesible a todas la mujeres que se acerquen o llamen al sindicato, la afiliación es condición necesaria para inscribirse en la bolsa de trabajo, realizar una consulta con un abogado o participar de los cursos de capacitación - aunque éstos son también gratuitos para las afiliadas a la obra social y las beneficiarias de los planes de capacitación y empleo.

Pese a que se trata de una porción reducida del conjunto de las trabajadoras que se insertan en esta actividad, en ella se manifiesta la enorme heterogeneidad que caracteriza el universo complejo del trabajo en el servicio doméstico. Las mujeres que acuden al sindicato, lo hacen para buscar un empleo a través de su bolsa de trabajo, para solicitar asistencia jurídica en caso de conflicto con sus empleadores o para iniciar trámites jubilatorios y sobre todo para solicitar información. Según las recepcionistas, las consultas más frecuentes responden a casos de despido o de incum- plimiento de los aportes patronales. Pero cada caso es un mundo, una historia particular sobre la que se calculan los aportes adeudados, las indemnizaciones o el margen de negociación con el que cuenta la empleada en función de la modalidad de trabajo, la calidad de la relación con los empleadores o su urgencia en contar con recursos económicos.

Sentada en la sala de espera, una mujer de unos cuarenta años comenta, mientras aguarda que se desocupe una de las dos recepcionistas, que viene a consultar si su sueldo se corresponde con los salarios mínimos del sector. Mientras tanto, otra mujer le expone su caso a una de las empleadas del sindicato. Le cuenta que sus empleadores acaban de despedirla y que además adeudan el último año de aportes previsionales. La recepcionista calcula en base a las horas de trabajo, sueldo y antigüedad: "decile que te pague 2.800 y que te ponga al día con los aportes. Si no quiere, negocia una parte y si no, volva el jueves a hablar con el abogado". Otra afiliada solicita una cita con el abogado para realizar una consulta sobre el caso de una amiga que trabajaba seis horas de lunes a sábados para una familia y le fueron negadas las vacaciones que solicitó para visitar a su hijos en Perú, su país de origen. Una tercera empleada trabaja "cama adentro", sus empleadores planean instalarse durante los tres meses de verano en Uruguay y quieren que los acompañe; ella no está segura de querer hacerlo y prefiere consultar su caso con un abogado. Estos diferentes casos relevados en la sala de espera del sindicato, manifiestan la enorme heterogeneidad de situaciones y problemáticas a las que están confrontadas aquellas que se insertan en el sector, donde dimensiones centrales de la experiencia de trabajo dependen de una negociación individual y personalizada con los empleadores.

Esta primacía de los servicios de asesoramiento individual tiene efectos importantes sobre la percepción que las trabajadoras construyen de la entidad gremial:

Llegó al local del sindicato cerca de las 4 de la tarde. Una de las recepcionistas habla por teléfono, mientras la segunda atiende a las mujeres que esperan. La mujer que está sentada a mi derecha parece molesta. Me dice que el abogado todavía no llegó, tiene una hora de retraso, se supone que llega a las 3 y ya son las 4 y aún no empezó a atender. Ella lleva una hora esperando: "no puede ser, porque el gobierno les paga por el trabajo que hacen y tienen que llegar a horario como todo el mundo". Me lo repite y agrega "además le pagamos nosotros todos los meses con los 3 pesos que pagamos". Me cuenta que cuando llegó para hacer la consulta con el abogado, la recepcionista le dijo que no estaba al día con su cuota, pero que se equivocaba, porque ella había pagado el trimestre entero, hasta 
julio. La recepcionista le propuso entonces que pague hasta septiembre, pero ella no quiso porque prefiere pagar trimestre a trimestre, por si se queda sin trabajo... (Notas de campo, 14 abr. 2009)

Como en el caso anterior, las visitas de las afiliadas suponen muy poca implicación con el funcionamiento del sindicato. Desde la perspectiva de las trabajadoras, éste aparece como una entidad proveedora de servicios, que es prácticamente asimilada a una dependencia pública. En la mayoría de los casos, se trata de consultas puntuales, que remiten casi exclusivamente a las problemáticas (y las posibles resoluciones) de una situación individual. Si bien el sindicato constituye un espacio fundamental donde se intercambian experiencias e información, la primacía de lo puntual y lo individual no facilita la construcción de una categoría homogénea de trabajadoras.

Frente a lo que sucede en los locales de atención al público del sindicato, la escuela de capacitación es un mundo a la vez opuesto y complementario. La participación sistemática y regular que implican los cursos de capacitación contrasta con la visita puntual al sindicato. Y sobre todo frente a la particularidad irreductible de cada experiencia individual y cotidiana de trabajo, la escuela es el mundo de la experiencia compartida, que no se limita a esas dos o tres horas que dura cada curso, como sugieren las notas siguientes, extraídas de la observación de un curso de cocina:

La profesora es un torbellino. Habla fuerte, está pendiente de todo lo que sucede en la cocina, dinámica, rápida, cocina, hace, mientras explica lo que hace, distribuye tareas entre las cinco mujeres, con cofias y delantales azules a rayas, que la siguen. Parece llevarse muy bien con el resto del grupo. Me cuenta, mientras trabaja, que ella hace mucho hincapié en la cuestión de la higiene y la seguridad: mantener las manos limpias, evaluar los productos con los que están trabajando, etc. El curso es animado y un poco caótico. El ambiente es festivo. Las mujeres no dejan de hablar en ningún momento, mientras cocinan se ríen, hacen chistes [...] Al final del curso, preparan té y mate cocido para todas y se reparten las tortas que estuvieron decorando. Cuando salimos, una de ellas dice "hasta la semana que viene... bah, a vos te veo todos los fines de semana" dirigiéndose a la que está a mi derecha. Otras dos mujeres salen juntas y se instalan en el café de la esquina. (Notas de campo 06 nov. 2008)

Más allá de los saberes y las técnicas aprendidas, lo que las mujeres que participan de los cursos de capacita- ción destacan en sus relatos, es la posibilidad de adquirir un espacio de sociabilidad. Un grupo de pertenencia para compartir esas tardes, organizar salidas los fines de semana, mantenerse en contacto. Como señala Isabel, una participante de los cursos de capacitación, en una de nuestras conversaciones: "Yo empecé como un hobby y ahora me gusta muchísimo. Somos un grupo bastante unido con las chicas. Y bueno, nos hacemos amigas que es lo más importante para mí". Es el caso también de Dora, que completó varios cursos de la formación profesional:

Yo vine a renovar el carnet de la obra social y vi el cartelito de los cursos y bueno, dije, voy a probar a ver qué es. Yo me planteé la cosa así, si no aprendo, bueno, me distraigo, porque la mayoría de las cosas, yo las sé hacer. Pero bueno, era como un espacio para mí, y la pasaba tan bien que seguí. Es un espacio para mí, yo vengo, me divierto, me relaciono con gente, a veces escuchas los problemas de los demás, me gusta relacionarme y tener ese espacio.

Como en el relato de Dora, la escuela de capacitación constituye, para las participantes, una posibilidad de contar con un espacio propio, en los dos sentidos: un espacio que les pertenece y un espacio de pertenencia. Pese a que la llegada a la Escuela de capacitación está vinculada a la ocupación en la que se insertan, el espacio propio que allí construyen se contrapone radicalmente con la experiencia cotidiana de trabajo. El carácter colectivo de los cursos se contrapone al aislamiento que caracteriza la manera en que realizan día a día su trabajo. Pero además, el carácter recreativo y social que las participantes le atribuyen a esas actividades diluye prácticamente el vínculo con el trabajo doméstico remunerado (que es la razón primera por la que llegaron a los cursos). En ese espacio, las participantes no son empleadas domésticas, sino que están cumpliendo otros roles: son "estudiantes" o "compañeras" compartiendo un curso de cocina. En esa ruptura, parece desdibujarse también la relación de ese espacio con el sindicato ${ }^{20}$.

Desde la perspectiva de las trabajadoras, las visitas a los locales de atención al público del sindicato responden a consultas y trámites puntuales, que no escapan a la particularidad de cada experiencia individual de trabajo en el servicio doméstico. La escuela de capacitación, en cambio, es el espacio de la experiencia compartida. Sin embargo, en los modos de apropiación de sus cursos y actividades por parte de las participantes, más allá de la adquisición de saberes y técnicas, lo que privilegian es la construcción de una sociabilidad que les permite adquirir un rol diferente al de empleadas domésticas. En ambos casos se manifiestan las dificultades que las

20 Después de una entrevista que realizamos en la escuela de capacitación, Margarita me relata un conflicto con un empleador y me cuenta que está planeando consultar a un abogado. Le comento entonces que puede solicitar los servicios de los abogados del sindicato. Margarita me pide los datos del sindicato, sin notar que estábamos en un local que éste comparte con la obra social. 
particularidades de este sector de actividad plantean a la organización de las trabajadoras.

\section{Reflexiones finales}

El impacto de las transformaciones recientes en la legislación laboral y de las iniciativas estatales en la organización sindical de las trabajadoras domésticas es significativo. El crecimiento del empleo registrado y de las posibilidades de acceso a una cobertura de salud para un mayor número de trabajadoras, han dado un impulso importante a la afiliación, primero a la obra social y luego al sindicato. En efecto, el crecimiento acelerado de la obra social ha facilitado el contacto entre la entidad gremial y sus potenciales afiliadas y ha consolidado ambas entidades.

Sin embargo, como no dejan de destacar los representantes sindicales, la desvalorización que pesa sobre esta forma de empleo sigue fragilizando, pese al contexto favorable y al crecimiento de la entidad gremial, su posición frente a sus interlocutores institucionales, ya sean organismos estatales u otros gremios. En ese marco, la entidad opta por privilegiar el desarrollo de una oferta de servicios, con el objetivo de construir y revalorizar, para sus representadas, una categoría profesional de pertenencia. La profunda heterogeneidad que caracteriza las situaciones de trabajo en el servicio doméstico constituye un obstáculo importante en esta línea de acción del sindicato. Las transformaciones recientes en la regulación estatal, al fortalecer el estatuto de trabajador "autónomo", acentúan esta diversidad. Desde nuestra perspectiva, la gran heterogeneidad de problemáticas con las que las trabajadoras recurren al sindicato es correlato de ese fortalecimiento del estatuto de trabajador independiente. Un estatuto donde dimensiones centrales que hacen a la experiencia de trabajo quedan excluidas de los sistemas de regulaciones colectivas que constituyen el derecho laboral y las protecciones sociales.

Frente a esa enorme heterogeneidad, el rol de la escuela de capacitación se vuelve central. Se trata de revalorizar los saberes asociados al trabajo doméstico y de homogeneizar las técnicas, las competencias y las acreditaciones. Los discursos de las participantes no parecen, por el momento, dar cuenta de una apropiación de la estrategia de profesionalización promovida por el sindicato. Sin embargo, el carácter grupal de las actividades allí realizan, la construcción de un ámbito de sociabilidad, la adquisición de nuevos roles, constituyen elementos valiosos para las participantes. Dan lugar, en particular, a la construcción colectiva de un espacio "propio", que puede sentar las bases para el desarrollo de un sentido de pertenencia a una categoría colectiva de trabajadoras.

\section{Referencias}

AFIP. Estimación de la Informalidad Laboral (2003-2006). Disponível em: <http://www.afip.gov.ar>. Acesso em: 2010.

BARBEITO, Alberto; LO VUOLO, Rubén. La nueva oscuridad de la política social. Del estado populista al neoconservador. Buenos Aires: CIEPP/Miño Dávila, 1998.

CHANEY Elsa; GARCÍA CASTRO, Mary (Eds.) $M u$ chacha, cachifa, criada, empleada, empregadinha, sirvienta y más nada, de. Caracas: Nueva sociedad, 1993.

CONTARTESE, Daniel. Caracterización del servicio doméstico en la Argentina. Buenos Aires: MTEySS, 2010

GOGNA, Mónica. Empleadas domésticas en Buenos Aires. In: CHANEY, Elsa; GARCÍA CASTRO, Mary (Eds.). Muchacha, cachifa, criada, empleada, empregadinha, sirvienta y más nada. Caracas: Nueva sociedad, 1993. p. 81-98.

GOLDSMITH, Mary. Disputando fronteras: la movilización de las trabajadoras del hogar en América Latina. Amérique Latine Histoire et Mémoire. Les Cahiers ALHIM, n. 14, 2007.

JAMES, Daniel. Resistencia e integración. El peronismo y la clase trabajadora argentina 1946-1976. Buenos Aires: Sudamericana, 1990.

LAUTIER, Bruno. Las empleadas domésticas latinoame- ricanas y la sociología del trabajo: algunas observaciones acerca del caso brasileño. Revista Mexicana de Sociología, México, año 65, n. 4, p. 789-814, oct-dic. 2003.

MACHADO, José Daniel. Acceso al ámbito de protección del decreto 326/56 para trabajadores del servicio doméstico. Revista de Derecho Laboral, Buenos Aires, p. 277317, 2003.

MARSHALL, Adriana; PERELMAN, Laura. Sindicalización: incentivos en la normativa sociolaboral. Cuadernos del IDES, Buenos Aires, n. 4, 2004.

OIT. Trabajo decente para los trabajadores domésticos. OIT, Ginebra, 2009.

SCHELLEKENS, Thea; VAN DER SCHOOT, Anja. Trabajadoras del hogar en Perú: el difícil camino a la organización. In: CHANEY, Elsa; GARCÍA CASTRO, Mary (Eds.). Muchacha, cachifa, criada, empleada, empregadinha, sirvienta y más nada. Caracas: Nueva Sociedad, 1993. p. $255-268$.

SENÉN GONZÁLEZ, Cecilia; HAIDAR, Julieta. Los debates acerca de la revitalización sindical y su aplicación en el análisis sectorial en la Argentina. Revista Latinoamericana de Estudios del Trabajo, 2da. Época, n. 22.

VIDAL, Dominique. Les bonnes de Rio. Emploi domestique et société démocratique au Brésil. Lille: Septentrion, 2007. 


\title{
Trade union strategies and government initiatives in the domestic service sector in the city of Buenos Aires: the impulse and its limits
}

\begin{abstract}
Domestic employment is one of the main sources of urban female employment in Argentina. As in other countries in the region, this occupation has been characterized historically by the high weight of informality and the delay of the specific legislation that regulates it on the general framework of labor laws. But a decade ago, the sector recorded profound changes, particularly the concern that state regulation. These changes involved the extension of the possibilities of access to employment and registered social protections to a larger number of maids. These initiatives were accompanied by practical training programs specifically geared to the maids in the city of Buenos Aires, were developed with the active participation of trade unions in the sector. From the basis of a qualitative study, this article goal is to analyze the effects of these changes in the functioning of trade unions in the sector and the relationship they establish with the workers.
\end{abstract}

Keywords: domestic employment; trade unions; training programs; Argentina.

\section{Estratégias sindicais e iniciativas estatais no setor do serviço doméstico na cidade de Buenos Aires: o impulso e seus limites}

\begin{abstract}
Resumo
O emprego doméstico constitui uma das principais fontes de emprego feminino urbano na Argentina. Como em outros países da região, esta ocupação foi caracterizada, historicamente, pelo peso elevado da informalidade e pelo atraso da legislação especifíca que regula o marco geral das leis do trabalho. Porém, há uma década, o setor registra profundas transformações que concernem particularmente na regulamentação estatal. Essas transformações implicaram na extensão das possibilidades de acesso ao emprego registrado e às proteções sociais para um maior número de empregadas domésticas. Essas iniciativas foram acompanhadas pela implantação de programas de formação e capacitação especificamente dirigidos às empregadas domésticas que, na cidade de Buenos Aires, foram desenvolvidos com a participação ativa de uma das organizações sindicais do setor.

Baseado en um estudo qualitativo, o objetivo deste artigo é analisar os efeitos destas transformações no funcionamento dos sindicatos do setor e a relação que estes estabelecem com as trabalhadoras.
\end{abstract}

Palavras-chave: trabalho doméstico; sindicatos; capacitação; Argentina.

Data de recebimento do artigo: 30-11-2010

Data de aprovação do artigo: 06-01-2011 